\title{
Removal of Model Organic Precursors by Coagulation
}

\author{
E. E. Chang'; P. C. Chiang ${ }^{2}$; H. J. Hsing ${ }^{3}$; and S. Y. Yeh ${ }^{4}$
}

\begin{abstract}
Low-molecular-weight organics, i.e., phloroglucinol (P), resorcinol (R), and p-hydroxybenzoic acid (PHBA), were selected as the target compounds to evaluate their removal and precursor reduction efficiency by coagulation under the presence of high-molecularweight compounds. The results of this investigation reveal that turbidity removal efficiencies can achieve $95 \%$ and above, but the total organic carbon removal for $\mathrm{P}, \mathrm{R}$, and PHBA are not remarkable, which are less than $20 \%$. The chlorine demand after 168 hour is: $\mathrm{P} \cong \mathrm{PHBA}>\mathrm{R}>$ humic acids (HA) $>$ tannic acid (TA); while the order of trihalomethanes (THM) formation is $\mathrm{R}>\mathrm{P}>\mathrm{PHBA}>\mathrm{HA}$ $>$ TA, which is strictly dependent upon the nature of the model compounds. By applying the developed dissolved organic carbon (DOC) removal model, both the maximum adsorption capacity and the residual DOC can be well predicted after coagulation. In this developed model, the adsorption capacity (a) is a function of the sorbable part of organic compounds $\left(f_{\text {sorbable }}\right)$, which can be expressed as: $a=e^{2.67 f_{\text {sorbable }}}$, both shown in nature and synthetic water samples. The $f_{\text {nonsorb }}$ increased as the molecular weight (MW) of the target compounds decreased, suggesting that low-MW target compounds could not be easily adsorbed on the flocs.
\end{abstract}

DOI: 10.1061/(ASCE)1090-025X(2007)11:1(69)

CE Database subject headings: Coagulation; Chloride; Abatement and removal; Organic matter.

\section{Introduction}

The coagulation process has been applied in water treatment for decades, which is optimized primarily for the removal of turbidity for water. Natural organic matter (NOM) associated with suspended particles is also removed by coagulation, but the removal efficiency is variable, depending on the physical and chemical characteristics of the water and the operating conditions (Ratnaweera et al. 1999). However, the NOM reacts with chlorine, and forms disinfection by-products (DBPs), which are the major health concern (Rook 1976). The formation of DBPs depends on the following factors: $\mathrm{pH}$, temperature, the amount of NOM, etc.; trihalomethanes (THMs) are the most important DBPs species formed after chlorination the concentration of which is dependent on the amount of NOM (Singer 1999; Chaiket et al. 2002). Aquatic NOM consists of humic substance, which may carry weakly acidic functional groups, such as carboxylic and phenolic groups (Cook and Langford 1998); furthermore, different molecular sizes of NOMs may have different contributions to THM formation (Plummer and Edzwald 2001). Low-

\footnotetext{
${ }^{1}$ Professor, Dept. of Biochemistry, Taipei Medical Univ., $250 \mathrm{Wu}$-Shin St., Taipei, Taiwan 110, R.O.C. E-mail: eechang@tmu.edu.tw

${ }^{2}$ Professor, Graduate Institute of Environmental Engineering, National Taiwan Univ., 71 Chou-Shan Rd., Taipei, Taiwan 106, R.O.C. (corresponding author). E-mail: pcchiang@ntu.edu.tw

${ }^{3}$ Researcher, National Science and Technology Center for Disaster Reduction, 3F, 106, Ho-Ping East Road, Taipei, Taiwan 106, R.O.C. E-mail: hjhsing@ncdr.nat.gov.tw

${ }^{4}$ Graduate Student, Graduate Institute of Environmental Engineering, National Taiwan Univ., 71 Chou-Shan Rd., Taipei, Taiwan 106, R.O.C.

Note. Discussion open until June 1, 2007. Separate discussions must be submitted for individual papers. To extend the closing date by one month, a written request must be filed with the ASCE Managing Editor. The manuscript for this paper was submitted for review and possible publication on June 26, 2006; approved on June 26, 2006. This paper is part of the Practice Periodical of Hazardous, Toxic, and Radioactive Waste Management, Vol. 11, No. 1, January 1, 2007. CASCE, ISSN 1090-025X/2007/1-69-76/\$25.00.
}

molecular-weight organic matter, like resorcinol (R), phloroglucinol (P), and p-hydroxybenzoic acid (PHBA), were considered to be contributors to high-DBP formation (Chang et al. 2004), which has been proven to be unfavorable to conventional potable water treatment, like the coagulation process (Bekbolet et al. 2005).

For controlling the formation of DBP, regulatory agencies require effective removal of TOC by coagulation (States and Tomko 2002; van Leeuwen et al. 2005). Unless the NOM of the raw water has a low total organic carbon (TOC) concentration, the required coagulant dosages are determined by the content of NOM in a water supply rather than by turbidity (O'Melia et al. 1999). The higher-molecular weight of NOM with the hydrophobic fraction was removed readily by coagulation (White 1997; Collins et al. 1986).

The amount of dissolved organic carbon (DOC) in NOM could serve as the baseline information for the tendency of DBP formation. Thus, the prediction of DOC removal could be used to depict the remaining DOC after coagulation and the DBP formation after chlorination. A developed DOC removal model is presented, which was based on the Langmuir isotherm theory with the following assumptions (Kastl et al. 2004):

- DOC removal is mainly the result of adsorption onto metal hydroxide floes formed during coagulation.

- DOC consists of three fractions: humic acid (associated with $\mathrm{pH}$ ), nonpolar (adsorption is independent of $\mathrm{pH}$ ), and nonsorbable (not removed during coagulation, independent of $\mathrm{pH}$ ).

- The maximum sorption capacity does not vary with $\mathrm{pH}$. The model is shown in Eq. (1) with some parameters

$$
\frac{\mathrm{DOC}_{\text {nonpolar }, 0}-\mathrm{DOC}_{\text {nonpolar }, 1}}{D}=\frac{a \times b \times \mathrm{DOC}_{\text {nonpolar }, 1}}{1+b \times \mathrm{DOC}_{\text {nonpolar }, 1}}
$$

where $D=$ alum dose (meq/L); $A=$ maximum DOC adsorption capacity (mg DOC/meq-alum); $b=$ adsorption constant (mg DOC/ $\mathrm{L}) ; \quad \mathrm{DOC}_{0}=$ initial $\mathrm{DOC}$ concentration $(\mathrm{mg} / \mathrm{L}) ; \mathrm{DOC}_{\text {nonpolar }, 0}$ $=f_{\text {nonpolar }} \times \mathrm{DOC}_{0}$; and $\mathrm{DOC}_{\text {nonpolar }, 1}=$ equilibrium concentration in water after the addition of the metal coagulant.

The constants, $a$ and $b$, in Eq. (1) could be calculated by 
Table 1. Physical/Chemical Properties of Model Compounds

\begin{tabular}{|c|c|c|c|c|c|}
\hline $\begin{array}{l}\text { Model } \\
\text { compound }\end{array}$ & $\begin{array}{l}\text { Humic } \\
\text { acid }\end{array}$ & $\begin{array}{c}\text { Tannic } \\
\text { acid }\end{array}$ & Phloroglucinol & Resorcinol & p-HBA \\
\hline Symbol & HA & TA & $\mathrm{p}$ & $\mathrm{R}$ & PHBA \\
\hline Molecular formula & - & $\mathrm{C}_{76} \mathrm{H}_{52} \mathrm{O}_{46}$ & $\mathrm{C}_{6} \mathrm{H}_{6} \mathrm{O}_{3}$ & $\mathrm{C}_{6} \mathrm{H}_{6} \mathrm{O}_{2}$ & $\mathrm{C}_{7} \mathrm{H}_{6} \mathrm{O}_{3}$ \\
\hline Molecular weight & 10-100 (thousand) & 1,700 & 126 & 110 & 138 \\
\hline Dissociation constant (pKa) & - & - & $\begin{array}{cc}\mathrm{pK}_{1} & 8.0 \\
\mathrm{pK}_{2} & 9.2 \\
\mathrm{pK}_{3} & 14\end{array}$ & $\begin{array}{c}\mathrm{pK}_{1} 9.30 \\
\mathrm{pK}_{2} 11.06\end{array}$ & $\begin{array}{l}\mathrm{pK}_{1} 4.48 \\
\mathrm{pK}_{2} 9.32\end{array}$ \\
\hline Solubility in water & - & $\begin{array}{l}2,857 \mathrm{~g} / \mathrm{L} \\
\quad\left(20^{\circ} \mathrm{C}\right)\end{array}$ & $\begin{array}{l}10 \mathrm{~g} / \mathrm{L} \\
\left(20^{\circ} \mathrm{C}\right)\end{array}$ & $\begin{array}{c}1,000 \mathrm{~g} / \mathrm{L} \\
\left(20^{\circ} \mathrm{C}\right)\end{array}$ & $\begin{array}{c}5,000 \mathrm{mg} / \mathrm{L} \\
\left(25^{\circ} \mathrm{C}\right)\end{array}$ \\
\hline SUVA $_{254}$ & - & - & 0.67 & 0.47 & 11.8 \\
\hline Provider & Aldrich & Merck & Acros & Acros & Merck \\
\hline
\end{tabular}

introducing various alum doses and applied pHs, which can serve as a reference for further study.

The objectives of this research were intended to: (1) discuss the effect of coagulation on the removal of low-molecular-weight (MW) model compounds, i.e., R, P, and PHBA, and highermolecular-weight model compounds, i.e., humic acid (HA) and tannic acids (TA); (2) develop an appropriate DOC removal model to predict the remaining dissolved organic carbon concentration after coagulation; (3) propose a set of water quality parameters to explore the competitive adsorption phenomena between HA and the rest of the model compounds; and (4) assess the disinfection by-products formation potential (DBPFP) for the selected model compounds after the coagulation process. The results of this research may be incorporated in a guideline for source water and treatment assessment.

\section{Materials and Methods}

\section{Chemicals}

The physical and chemical properties of the model compounds used in this research include phloroglucinol, resorcinol, p-hydroxybenzoic acid, humic acid, and tannic acid. Aluminum sulfate [alum, $\mathrm{Al}_{2}\left(\mathrm{SO}_{4}\right)_{3} \cdot 18 \mathrm{H}_{2} \mathrm{O}$ ] was used as the major coagulant source in this study, which was purchased from Kanto (Tokyo, Japan). Diluted $\mathrm{H}_{2} \mathrm{SO}_{4}$ and $\mathrm{NaOH}$ solutions were added to the stock solution for the purpose of $\mathrm{pH}$ adjustment. Calcium carbonate $\left(\mathrm{CaCO}_{3}\right)$ for alkalinity, bentonite for simulating the turbidity, sodium persulfate $\left(\mathrm{Na}_{2} \mathrm{~S}_{2} \mathrm{O}_{8}\right)$ and phosphoric acid $\left(\mathrm{H}_{3} \mathrm{PO}_{4}\right)$ for TOC analysis, chlorine standards, and ferrous ammonium sulfate (FAS) and potassium iodide (KI) for chlorine residue tests were purchased and prepared before conducting the experiments. The physical and chemical properties for these five target compounds are listed in Table 1.

\section{Preparation of Synthetic Water}

The synthetic water was composed of (1) TOC: $4.0 \mathrm{mg} / \mathrm{L}$ for HA, PHBA, R, and P; $3.0 \mathrm{mg} / \mathrm{L}$ for TA; (2) bentonite was added to make turbidity $=50 \mathrm{NTU}$, and (3) alkalinity: $100 \mathrm{mg} / \mathrm{L}$ as $\mathrm{CaCO}_{3}$. Bentonite used in this study may play two roles, one is to serve as a particle in the sample water, the other is the adsorption of the adsorbed matter.

\section{Experimental Procedure}

Experiments were conducted with an initial $\mathrm{pH}$ of 5 or 8.5. After the water was divided into beakers and alum was added into each sample, the jar test was turned on and the speed was adjusted to $100 \mathrm{rpm}$ for $3 \mathrm{~min}$, and then $30 \mathrm{rpm}$ for $15 \mathrm{~min}$. The $\mathrm{pH}$ of each sample was noted. After the settlement of floc for $20 \mathrm{~min}$, TOC, DOC, turbidity, and $\mathrm{UV}_{254}$ of the supernatant were analyzed for each sample. As chlorination proceeded, the samples were stored in the dark until a specific contact time ( $2 \mathrm{~min} / \mathrm{sample}$ within $10 \mathrm{~min} ; 10 \mathrm{~min} / \mathrm{sample}$ within $1 \mathrm{~h}$; and 1, 3, 6, 8, 10, 24, 48, and $168 \mathrm{~h}$ ). The residual chlorine and DBP concentrations of each sample were then determined.

DBPFP, including THM and HAA, formation potential was measured after a 7-day (168-h) incubation period with sodium hyperchlorite (Merck) solution according to Standard Methods (APHA 1998). A 168-h chlorine consumption study was performed using $28 \mathrm{mg} / \mathrm{L}$ chlorine dosage $\left(\mathrm{as}_{2}\right)$ to determine the chlorine consumption (168 h) and trihaloromethane formation potential (THMFP). The 13\% free chlorine (sodium hypochlorite) stock solution and phosphate buffer $(\mathrm{pH} 7.0)$ were held at room temperature throughout these chlorination experiments. The applied chlorine dose was about nine times the DOC dosage. A blank was prepared using the same amount of deionized ultrafiltered water chlorinated under the same conditions as the sample. Samples were chlorinated in 5-L glass bottles and then carefully transferred into 150 amber glass bottles with Teflon-lined caps. A separate bottle was used for each reaction time investigated. Until analyzed, the samples were kept headspace free in a dark at room temperature. Chlorine residual and DOC, UV adsorption were measured at different times for each bottle. The experimental design flow chart is presented in Fig. 1.

\section{Analytical Methods}

Chlorine concentration was measured by N,N-diethyl-pphenyldiamine (DPD) titration methods. DOC (TOC), $\mathrm{UV}_{254}, \mathrm{pH}$, and DBP formation potentials were measured in water samples. All analyses, unless otherwise noted, were performed according to the 20th edition of the Standards Methods (APHA 1998). Water samples for DOC and UV analyses were first filtered through a prewashed $0.45 \mu \mathrm{m}$ filter and then determined by a TOC analyzer (O.I. Corporation Model 700, Tex.) and UV spectroscopy (Hitachi U-2000, Tokyo), respectively. Because bromide ions were not 


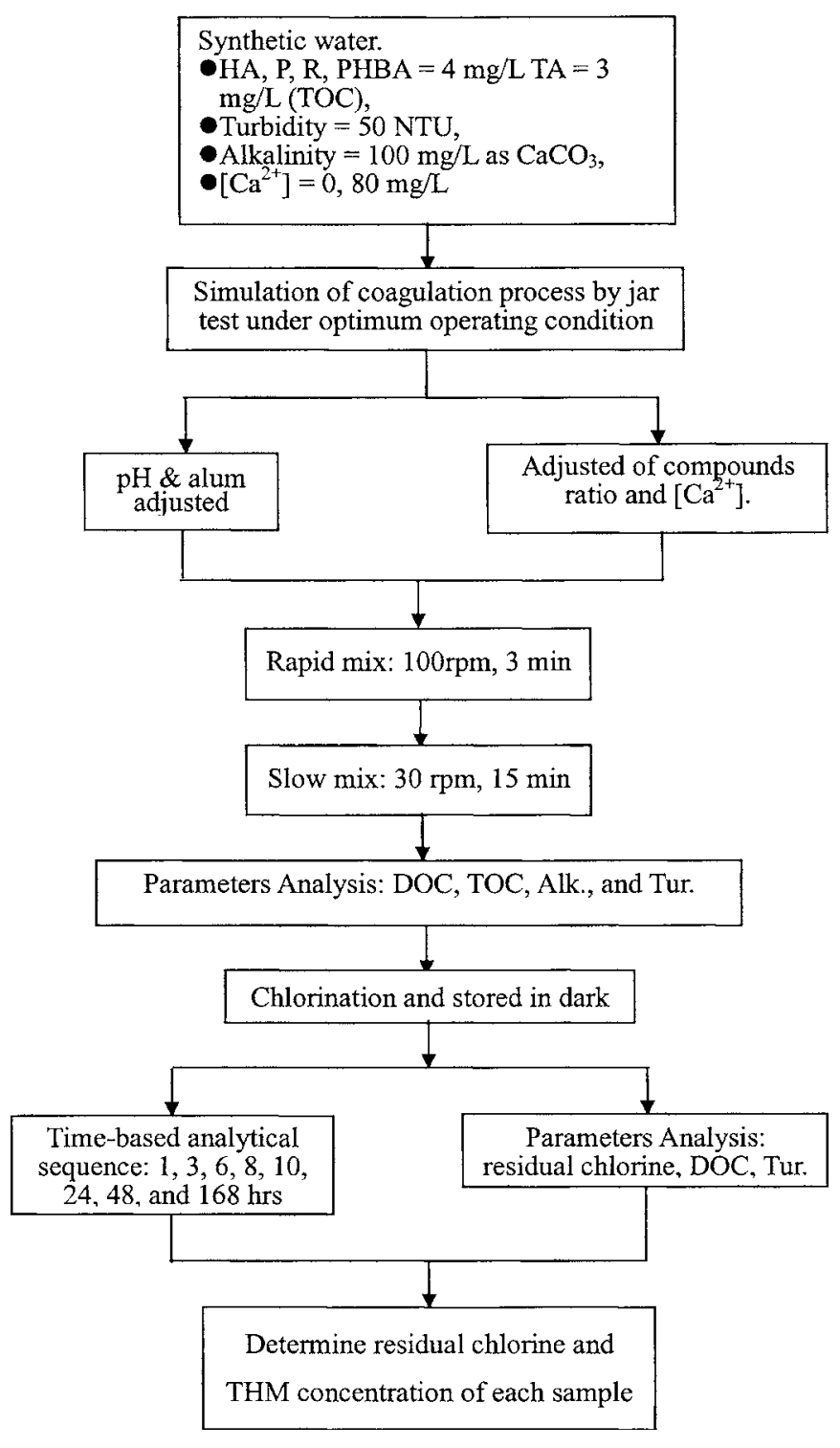

Fig. 1. Experimental design flow chart

present in this study, trihalomethane and chloroacetic acids (CAA) were analyzed using a gas chromatograph with an electron capture detector (model HP 6890 GC/ECD, Agilent Technologies, Calif.), the samples were injected into a purge and trap autosampler to expel water content, using the detailed method presented by USEPA (USEPA 1995).

All the glassware was washed in an acid and rinsed with Milli-Q (Waters, Mass.) water to minimize the background level.
Duplicate analyses were performed on each sample, and the average was reported. If the difference between the two values was greater than $15 \%$, a third analysis was performed, and the average of all three values was reported.

\section{Results and Discussion}

\section{TOC (or DOC), Turbidity, and DBPFP Removal for Model Compounds by Coagulation}

The synthetic water was prepared by adding five target compounds into distilled water and the TOC concentration were preadjusted as mentioned, which also contained 50 NTU of turbidity with alkalinity $=100 \mathrm{mg} / \mathrm{L}$ (as $\mathrm{CaCO}_{3}$ ). According to previous research, the optimum dosage of aluminum sulfate [alum, $\left.\mathrm{Al}_{2}\left(\mathrm{SO}_{4}\right)_{3} \cdot 18 \mathrm{H}_{2} \mathrm{O}\right]$ for effective coagulation was determined to be at $40 \mathrm{mg} / \mathrm{L}$, while the $\mathrm{pH}$ was adjusted to be at 5.0 (Tang 2003).

As shown in Table 2, the coagulation process was effective for removing turbidity in the presence of various organics, i.e., turbidity removal was acceptable in all cases of this investigation with more than $95 \%$ efficiency and the residual turbidity was less than 2.5 NTU, suggesting that the coagulation was feasible in turbidity removal. For experiments involving $\mathrm{HA}$ and TA, the TOC removal was higher than 70\%; however, TOC removal of R, $\mathrm{P}$, and PHBA was less than $20 \%$. Without a polymer addition, adsorption and charge neutralization are presumed to be the major mechanisms for removing TOC (or DOC).

Table 3 summarizes the chlorine consumption and THM formation of the selected organic precursors after the coagulation process. HA contained more active sites than TA, while TA contained deactivating ester groups, which might block the hydrolysis process. Therefore, the chlorine consumption for TA was less than HA, which reflected that on the fused-ring structures-one of the aromatic carbon sites adjacent to the C1-hydroxyl group was inverted to electrophilic substitution by chlorine.

For $\mathrm{P}$ and $\mathrm{R}$, the higher $\left[\mathrm{Cl}_{2}\right] /[$ substrate $]$ ratios were ascribed to the evidence that the pathway of conversion of the aromatic diol (or triol) precursors to chloroform involved a quantity of addition and substitution steps on singular structures. With the $\beta$-diketone structures of $\mathrm{R}$, its two activating - $\mathrm{OH}$ groups could release electrons rapidly, leading to the electrophilic addition and substitution reactions while chlorination was proceeding (Larson and Rockwell 1979; Gallard and Gunten 2002). It was implied that $\mathrm{R}$ is the most efficient precursor of chloroform among these five model compounds.

Furthermore, $\mathrm{P}$ with three $-\mathrm{OH}$ groups was not inclined to form chloroform. One possible explanation could be: $\mathrm{P}$ is highly symmetric and may form a resonance-stabilized intermediate,

Table 2. Summary of TOC, DOC, Turbidity, and Percent Removal of Five Model Compounds before and after the Coagulation Process

\begin{tabular}{|c|c|c|c|c|c|c|c|c|c|}
\hline \multirow[b]{2}{*}{$\begin{array}{l}\text { Synthetic } \\
\text { waters }\end{array}$} & \multicolumn{3}{|c|}{ TOC } & \multicolumn{3}{|c|}{ DOC } & \multicolumn{3}{|c|}{ Turbidity } \\
\hline & $\begin{array}{l}\text { Initial } \\
(\mathrm{mg} / \mathrm{L})\end{array}$ & $\begin{array}{l}\text { Residual } \\
\text { (mg/L) }\end{array}$ & $\begin{array}{c}\text { Removal } \\
(\%)\end{array}$ & $\begin{array}{l}\text { Initial } \\
(\mathrm{mg} / \mathrm{L})\end{array}$ & $\begin{array}{l}\text { Residual } \\
\text { (mg/L) }\end{array}$ & $\begin{array}{c}\text { Removal } \\
(\%)\end{array}$ & $\begin{array}{l}\text { Initial } \\
(\mathrm{mg} / \mathrm{L})\end{array}$ & $\begin{array}{c}\text { Residual } \\
(\mathrm{mg} / \mathrm{L})\end{array}$ & $\begin{array}{c}\text { Removal } \\
(\%)\end{array}$ \\
\hline HA & 4.4 & 1.2 & 72.7 & 3.9 & 0.6 & 84.6 & 47.6 & 2.2 & 95.4 \\
\hline TA & 2.9 & 0.7 & 75.9 & 1.9 & 0.6 & 68.4 & 31.7 & 0.5 & 98.4 \\
\hline $\mathrm{P}$ & 3.6 & 3.4 & 5.6 & 4.0 & 3.9 & 2.5 & 45.2 & 2.4 & 95.7 \\
\hline $\mathrm{R}$ & 3.7 & 3.2 & 13.5 & 3.2 & 2.3 & 28.1 & 46.1 & 1.8 & 96.0 \\
\hline PHBA & 3.9 & 3.6 & 7.7 & 3.9 & 3.8 & 2.6 & 33.6 & 0.9 & 97.3 \\
\hline
\end{tabular}


Table 3. Summary of Chlorine Demand and THM $\left(\mathrm{CHCl}_{3}\right)$ Formation after the Coagulation Process

\begin{tabular}{|c|c|c|c|c|}
\hline $\begin{array}{l}\text { Synthetic } \\
\text { waters }\end{array}$ & $\begin{array}{l}\text { Final } \\
\text { chlorine } \\
\text { demand } \\
(\mathrm{mg} / \mathrm{L})^{\mathrm{a}}\end{array}$ & $\begin{array}{c}\text { THM } \\
\text { formation } \\
{[\text { after } 168 \mathrm{~h}(\mu \mathrm{g} / \mathrm{L})]^{\mathrm{b}}}\end{array}$ & $\begin{array}{c}\text { Specific } \\
\text { THMFP } \\
{[(\mathrm{THM})(\mu \mathrm{g} / \mathrm{L}) / \mathrm{TOC}(\mathrm{mg} / \mathrm{L})]^{\mathrm{c}}}\end{array}$ & $\begin{array}{c}{\left[\mathrm{Cl}_{2}\right] /} \\
{[\text { substrate }]^{\mathrm{d}}}\end{array}$ \\
\hline HA & 6.81 & 88.5 & 73.1 & 5.6 \\
\hline TA & 2.88 & 20.3 & 29.0 & 4.1 \\
\hline $\mathrm{P}$ & 26.18 & 1943.5 & 570.0 & 7.7 \\
\hline $\mathrm{R}$ & 21.07 & 3173.0 & 979.3 & 6.5 \\
\hline PHBA & 25.35 & 209.2 & 58.5 & 7.1 \\
\hline
\end{tabular}

${ }^{\mathrm{a}}$ Final chlorine demand=chlorine consumption after $168 \mathrm{~h}$.

${ }^{\mathrm{b}}$ Without the bromide ion source, the Br-substituted products, $\mathrm{CHBrCl}_{2}, \mathrm{CHBr}_{2} \mathrm{Cl}$, and $\mathrm{CHBr}_{3}$ are negligible compared to chloroform. THM represents chloroform $\left(\mathrm{CHCl}_{3}\right)$ in this study.

${ }^{\mathrm{c}}$ Specific THMFP $=($ THM concentration after $168 \mathrm{~h}$ of chlorination $) /($ residual TOC after coagulation process $)$, in the units of $(\mu \mathrm{g} / \mathrm{L}) /(\mathrm{mg} / \mathrm{L})$.

$\mathrm{d}\left[\mathrm{Cl}_{2}\right] /[$ substrate $]=$ (final chlorine demand)/(residual TOC after coagulation process), in the units of $(\mathrm{mg} / \mathrm{L}) /(\mathrm{mg} / \mathrm{L})$.

which can impede the series of hydrolysis and decarboxylation with $\mathrm{C}-\mathrm{C}$ bond cleavage on the carbon site of the aromatic ring. However, for resorcinol, both $-\mathrm{OH}$ groups are located at an appropriate position to stabilize the transition state of the reaction through the donation of electron density. As for PHBA, being linked with the moderately deactivating constituent $(-\mathrm{COOH})$, the electron density on the benzene ring would be lowered during the ionization process of carboxyl groups. Consequently, it might be concluded that the order of chlorine demand after $168 \mathrm{~h}$ is: $\mathrm{P} \square \mathrm{PHBA}>\mathrm{R}>\mathrm{HA}>\mathrm{TA}$, while the order of THM (or HAA) formation is $\mathrm{R}>\mathrm{P}>\mathrm{PHBA}>\mathrm{HA}>\mathrm{TA}$, which is strictly dependent upon the nature of the model compounds, as shown in Table 3.

\section{Validation of DOC Removal Model}

The coagulation efficiency of R, P, and PHBA decreased due to the low dissociability and the competition between bentonite and model compound surfaces on to the adsorption sites of colloids. Without enough ionized structures, the charge neutralization mechanism was insignificant in the coagulation process. While dispersed in water in their small and molecular forms, few suspended particles could be enmeshed in the precipitates of $\mathrm{Al}(\mathrm{OH})_{3(\mathrm{~s})}$, suggesting that the bentonite removal was mainly the result of adsorption onto the metal hydroxide solid or enmeshment in the precipitates of $\mathrm{Al}(\mathrm{OH})_{3(\mathrm{~s})}$. In a previous report (Kastl et al. 2004), researchers had confirmed the above hypotheses and developed a DOC removal model [see Eq. (1)]. In this study, the model was validated and the parameters $(a$ and $b)$ were obtained from jar tests with three alum doses $(20,40$, and $60 \mathrm{mg} / \mathrm{L})$ and two $\mathrm{pH}$ values (5 and 8.5). The predicted remaining DOC $\left(\mathrm{DOC}_{\text {residual }}\right)$ could be determined by modifying Eq. (1) as

$$
\frac{\mathrm{DOC}_{\text {initial }}-\mathrm{DOC}_{\text {residual }}}{D}=\frac{a \times b \times \mathrm{DOC}_{\text {residual }}}{1+b \times \mathrm{DOC}_{\text {residual }}}
$$

According to the study by Tseng and Edwards (1999), for a given source, the fractions $(f)$ were constants, since DOC was associated with the dilutions or concentrations of the fractions in the same proportion. Therefore, the correlation among the fractions of nonsorbable $\left(f_{\text {nonsorb }}\right)$, HA $\left(f_{\text {ha }}\right)$, and nonpolar $\left(f_{\text {nonpolar }}\right)$ are expressed as follows:

$$
\begin{aligned}
\mathrm{DOC}_{\text {nonsorb }} & =f_{\text {nonsorb }} \times \mathrm{DOC}_{0} \\
\mathrm{DOC}_{\text {ha }, 0} & =f_{\text {ha }} \times \mathrm{DOC}_{0}
\end{aligned}
$$

$$
\begin{gathered}
\mathrm{DOC}_{\text {nonpolar }, 0}=f_{\text {nonpolar }} \times \mathrm{DOC}_{0} \\
f_{\text {nonsorb }}+f_{\text {ha }}+f_{\text {nonpolar }}=1
\end{gathered}
$$

The $f_{\text {nonpolar }}$ values were determined by measuring fractions removed at $\mathrm{pH} 8.5$, and $f_{\text {nonsorb }}$ could be determined by measuring fractions removed at a high alum dose $(60 \mathrm{mg} / \mathrm{L})$ at $\mathrm{pH}$. The information of $f_{\text {nonsorb }}, f_{\text {ha }}, f_{\text {nonpolar }}, a$, and $b$ for the five target compounds are listed in Table 4 . It was observed that HA represented a relatively high adsorption capacity $(12.0 \mathrm{mg} \mathrm{DOC} / \mathrm{meq}$ -alum) compared with $\mathrm{P}$ (2.6 mg DOC/meq alum), suggesting that DOC could be complexed well by the surface of metal hydroxide during coagulation, resulting in higher DOC removal. The low adsorption capacity indicates that the low-MW model compounds were removed difficulty by adsorption onto the metal hydroxide floes during coagulation. As a result, the reduction of $\mathrm{P}$, $\mathrm{R}$, and PHBA by adsorption was not an efficient removal mechanism in the course of coagulation.

In this developed model, the adsorption capacity $(a)$ is a function of $f_{\text {sorbable }}$ of organic compounds, which can be expressed as:

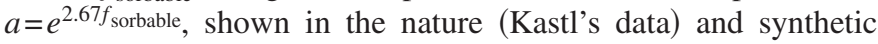
water (this study) samples with a $\mathrm{R}^{2}$ of 0.88 , as show in Fig. 2. Some other natural water samples were taken into account in Fig. 2 as well, indicating that a similar relationship between $a$ and $f_{\text {sorbable }}$ was also observed in both samples of natural water and synthetic water. Meanwhile, the adsorption characteristics $(b)$ of compounds were varied from one to another, suggesting that the $b$ value was independent to the $f_{\text {sorbable value and could not be pre- }}$ dicted in this study.

From Table 4, it is noted that the $f_{\text {nonsorb }}$ increased as the MW of the target compounds decreased, suggesting that the low-MW target compounds could not be easily adsorbed on the flocs. For the $f_{\text {sorbable, }}$, which was equal to the sum of $f_{\text {nonpolar }}$ and $f_{\text {ha }}$, the average of $f_{\text {sorbable }}$ was about 0.54 , which was similar to the average of that in natural water samples (0.51) (only $3 \%$ difference). The $f_{\text {nonpolar }}$ term reflected the hydrophobic fraction in the water samples, and the average of that was 0.30 , which was $13 \%$ above that in Kastl's data.

Fig. 3 presents the remaining DOC concentration $\left(\mathrm{DOC}_{\mathrm{obs}}\right)$ for the five monocompounds with the model predictions as well as the simulation data $\left(\mathrm{DOC}_{\mathrm{pre}}\right)$. It was noted that on average, the model provided a relatively good prediction of $\mathrm{DOC}_{\mathrm{obs}}$ after coagulation, especially for the low-MW compounds, and the higher turbidity reflected a relatively better prediction on DOC. The possible explanation would be that bentonite was associated with 
Table 4. Model Parameters for Five Monocompouds Treated with Alum

\begin{tabular}{|c|c|c|c|c|c|c|}
\hline Reference & Sample & $f_{\text {nonsorb }}$ & $f_{\text {nonpolar }}$ & $f_{\text {ha }}$ & $\begin{array}{c}a^{\mathrm{a}} \\
\text { (mg DOC/meq alum) }\end{array}$ & $\begin{array}{c}b^{\mathrm{b}} \\
(\mathrm{L} / \mathrm{mg} \text { DOC }) \\
\end{array}$ \\
\hline \multirow[t]{5}{*}{ This work } & HA & 0.188 & 0.672 & 0.14 & 12 & 417 \\
\hline & TA & 0.416 & 0.101 & 0.483 & 3.1 & 215 \\
\hline & $\mathrm{P}$ & 0.61 & 0.592 & 0.202 & 8.9 & 28 \\
\hline & $\mathrm{R}$ & 0.716 & 0.085 & 0.199 & 2.6 & 122 \\
\hline & PHBA & 0.791 & 0.068 & 0.142 & 2.7 & 33 \\
\hline \multirow[t]{6}{*}{ Kastl et al. (2004) } & West River & 0.482 & 0.235 & 0.183 & 9.0 & 60 \\
\hline & Potomic River & 0.545 & 0.265 & 0.19 & 2.8 & 152 \\
\hline & Chatahoochee River & 0.582 & 0.235 & 0.183 & 4.8 & 230 \\
\hline & Clinton Lake & 0.524 & 0.251 & 0.225 & 3.5 & 192 \\
\hline & Colorado River & 0.405 & 0.235 & 0.36 & 1.8 & 47 \\
\hline & Mississippi River & 0.454 & 0.241 & 0.305 & 3.2 & 299 \\
\hline
\end{tabular}

${ }^{\mathrm{a}} a=$ adsorption capacity in $\mathrm{mg}$ DOC/meq alum.

${ }^{\mathrm{b}} b=$ adsorption constant in $\mathrm{L} / \mathrm{mg}$ DOC.

adsorption, which did reflect the adsorption capacity of DOC in this model during the coagulation process. With the addition of $80 \mathrm{mg} / \mathrm{L} \mathrm{Ca}^{2+}$, the correlation between the model prediction and observed data was reasonably good, as shown in Fig. 4. It can be concluded that for monocompounds, this DOC removal model could provide a reasonable assumption to express the phenomenon of DOC adsorption onto metal hydroxide flocs during the coagulation process and resulted in predicting DOC removal more accurately.

\section{Effects of Humic Acid on the Removal of Low-MW Organic Precursors}

The removal of TOC, DOC, and turbidity between different ratios of HA to P, R, and PHBA are presented in Fig. 5. In Fig. 5(a), the turbidity removal efficiencies are all above $90 \%$ in any ratios of HA to low-MW target compounds, whereas the TOC removal is not significant among them, as seen in Fig. 5(c). For the DOC removal, it indicated that DOC was generally in congruent with the TOC removal, and the removal efficiencies decreased as the ratio of HA to the low-MW compound increasing, indicating that to increase the amount of low-MW model compounds could not

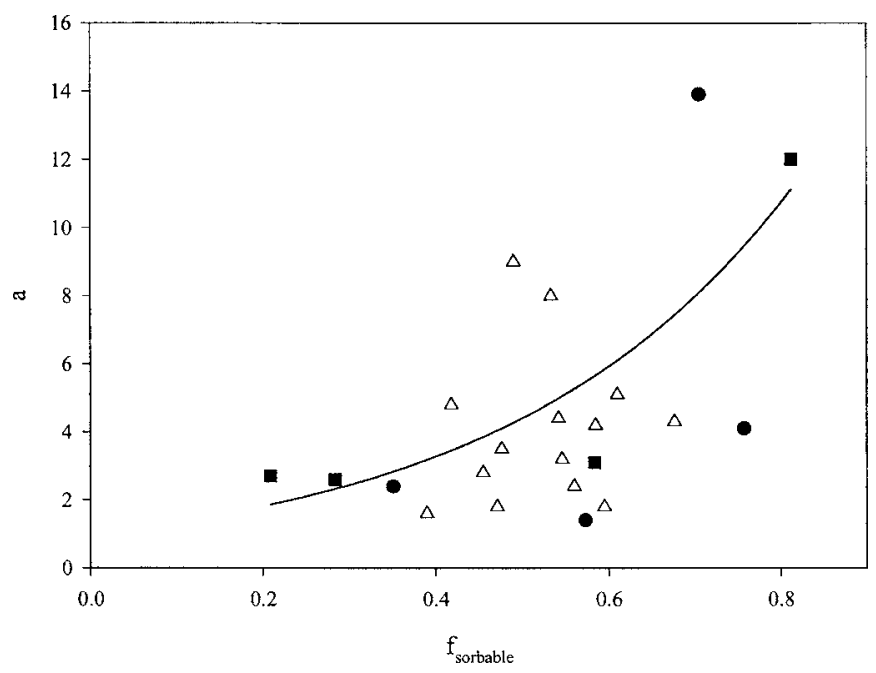

Fig. 2. Comparison of measured $\mathrm{DOC}\left[\mathrm{DOC}_{\mathrm{obs}}(\mathrm{mg} / \mathrm{L})\right]$ and predicted DOC $\left[\mathrm{DOC}_{\mathrm{pre}}(\mathrm{mg} / \mathrm{L})\right]$ for five monocompounds enhance the DOC removal. For compound $\mathrm{P}$ with $\mathrm{HA}$ as a case, as the ratios of HA to $\mathrm{P}$ ranged from 4:1, 4:2 to 4:3, approximately 63,39 , and $26 \%$ of DOC could be removed after coagulation. For $\mathrm{R}$, the corresponding DOC removal efficiencies were 62,44 , and $37 \%$, respectively; whereas for PHBA, they were 56, 46, and $31 \%$, respectively. The removal efficiency of DOC was decreased with the increasing concentration of low-MW compounds. For P and $\mathrm{R}$, the difference in DOC removal was less significant between $4: 2$ and $4: 3$.

Low-MW model compounds were unfavorable to coagulation while HA was remarkably reduced, which was observed in this study. Although the turbidity and TOC could reach a certain level of removals after coagulation, the efficiency of low-MW model compound removal was not remarkable, which was opposed to the hypothesis, i.e., the increasing ratio of HA to $\mathrm{P}$ (R and PHBA) might enhance the removal of low-MW model compounds via the coagulation process.

When increasing the chlorination time, the total DBP levels generally increased as the ratio of HA to low-MW model compounds increased. For the mixture of HA and P, the extent of DBP reached $2,400,3,600$, and $4,400 \mu \mathrm{g} / \mathrm{L}$, respectively, as seen in Fig. 6(a). But for the case of HA on PHBA, the levels of DBP were not as high as the cases of $\mathrm{P}$ and $\mathrm{R}$ - the level of PHBA case was only about one fifth of that of P and R [Fig. 6(c)]. Clearly, the

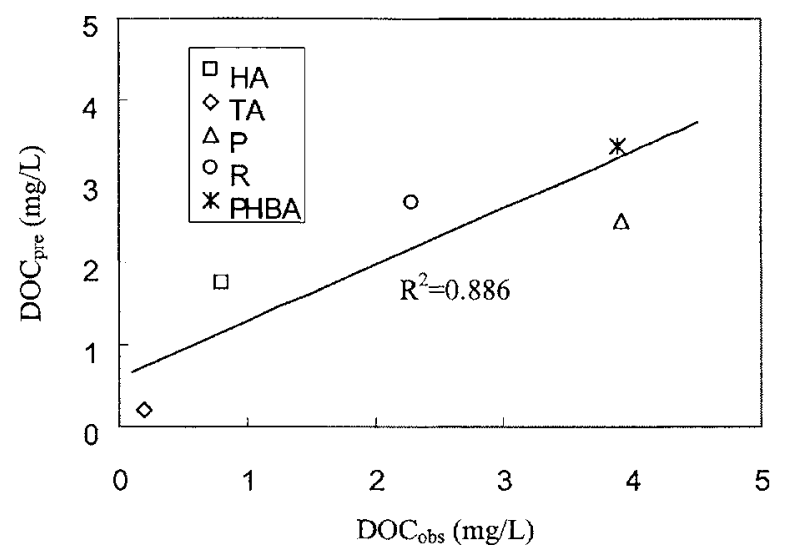

Fig. 3. Comparison of measured $\mathrm{DOC}\left[\mathrm{DOC}_{\mathrm{obs}}(\mathrm{mg} / \mathrm{L})\right]$ and predicted DOC $\left[\mathrm{DOC}_{\mathrm{pre}}(\mathrm{mg} / \mathrm{L})\right]$ for five monocompounds with the addition of $80 \mathrm{mg} / \mathrm{L} \mathrm{Ca}^{2+}$ 


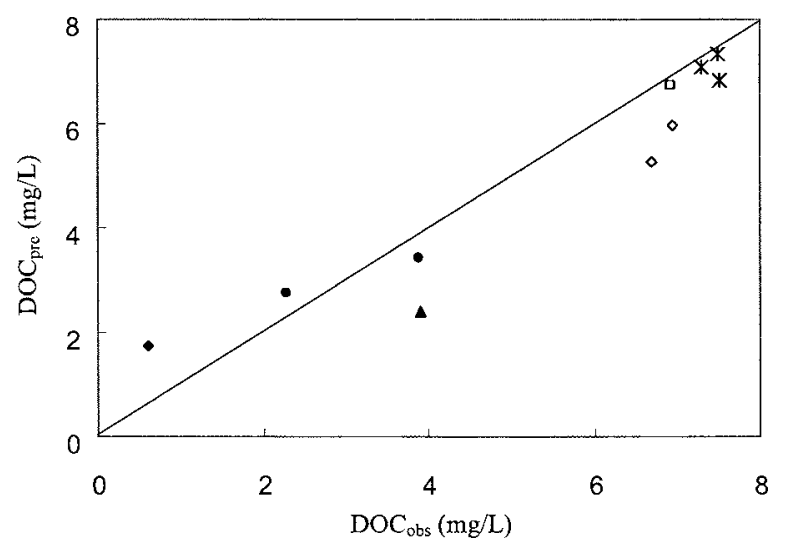

Fig. 4. Correlation between $a$ and $f_{\text {sorbable }}$ of target compounds: $\mathbf{\square}=$ four target compounds proposed in this work; $\boldsymbol{O}=$ four target compounds proposed in this work with $\left[\mathrm{Ca}^{+2}\right]=80 \mathrm{mg} / \mathrm{L} ; \square=$ data reorganized from Kastl et al. (2004)

higher ratio of HA to low-MW model compounds would lead to the higher amount of DBP concluded from these experiments. Among them, $\mathrm{R}$ was considered the most predominant precursors for chlorination, but it could not be removed effectively by coagulation compared with the other two low-MW compounds.

The HAA formation was explored and discussed in the case of $\mathrm{R}$ and HA, which follow a similar pattern to that in DBPs forma-
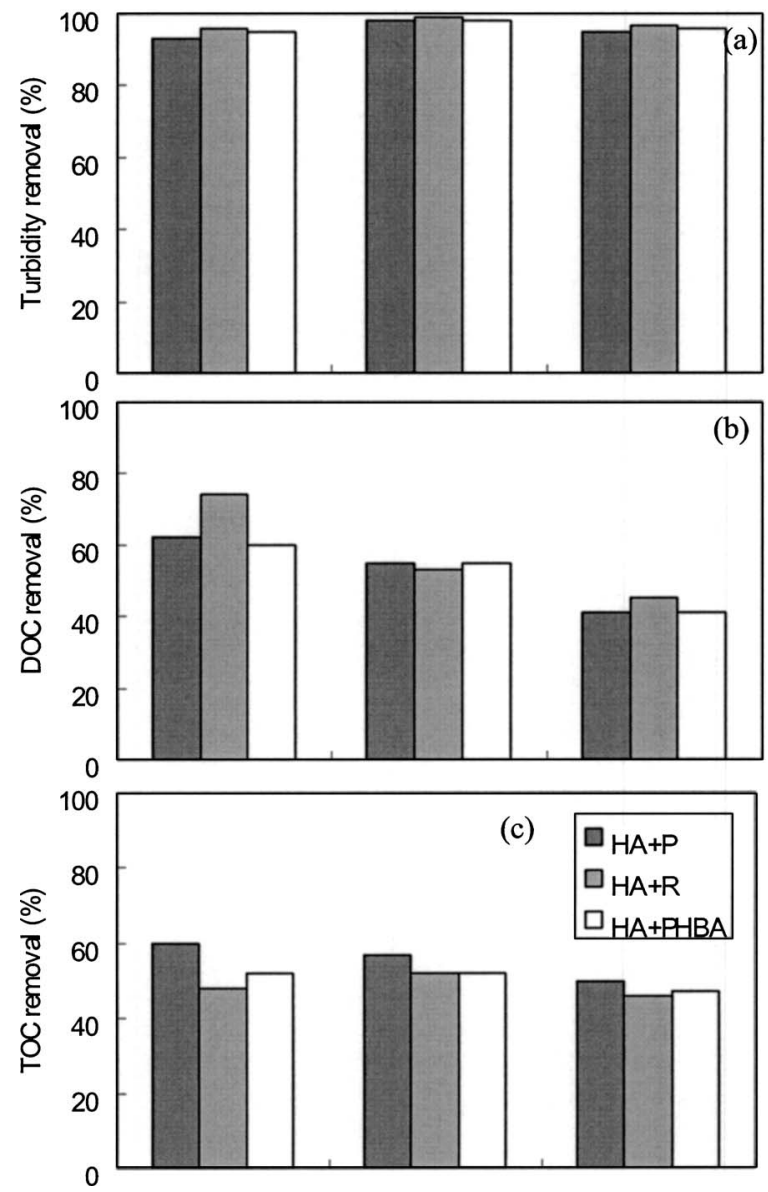

Fig. 5. Removal of (a) turbidity; (b) DOC; and (c) TOC between different proportions of bicompounds after coagulation

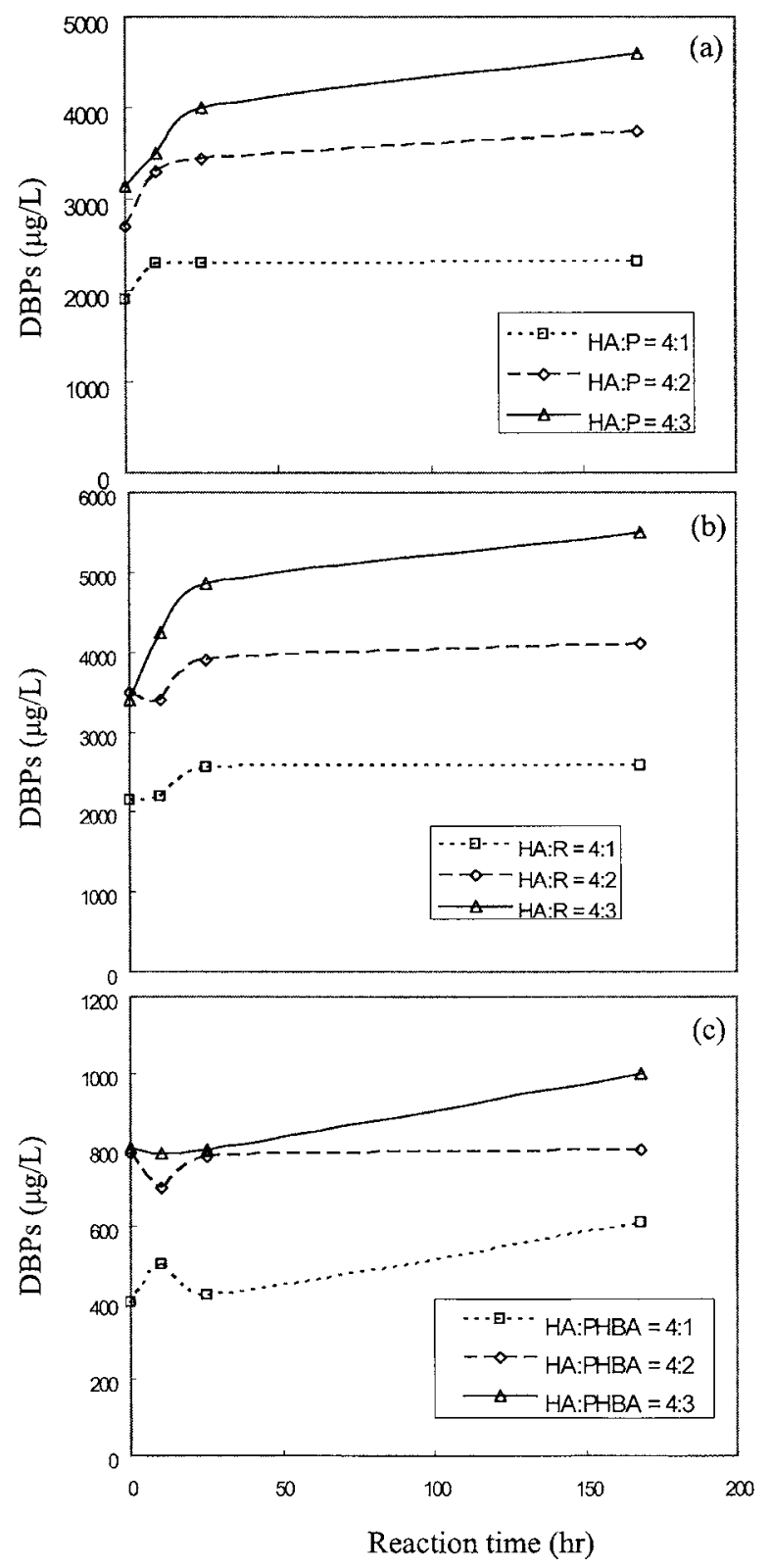

Fig. 6. DBP (THM+HAA) formation as a function of reaction time: (a) $\mathrm{HA}+\mathrm{P}$; (b) $\mathrm{HA}+\mathrm{R}$; and (c) $\mathrm{HA}+\mathrm{PHBA}$

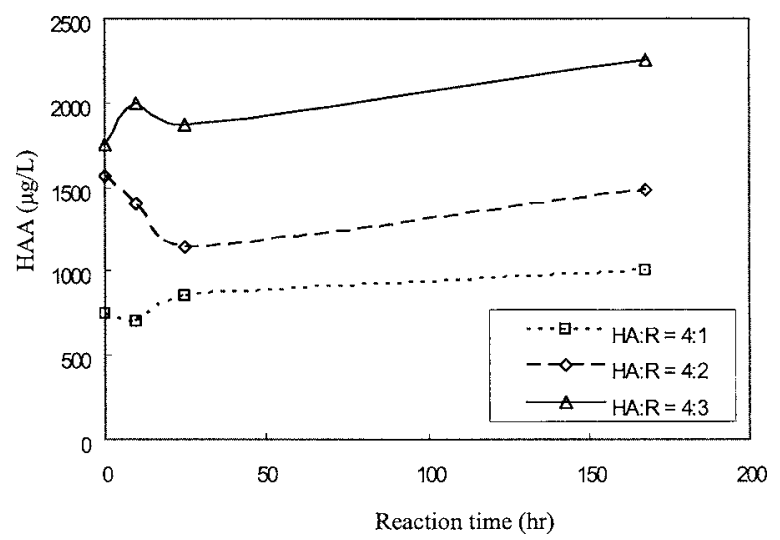

Fig. 7. HAA formation of HA:R under three combination ratios 

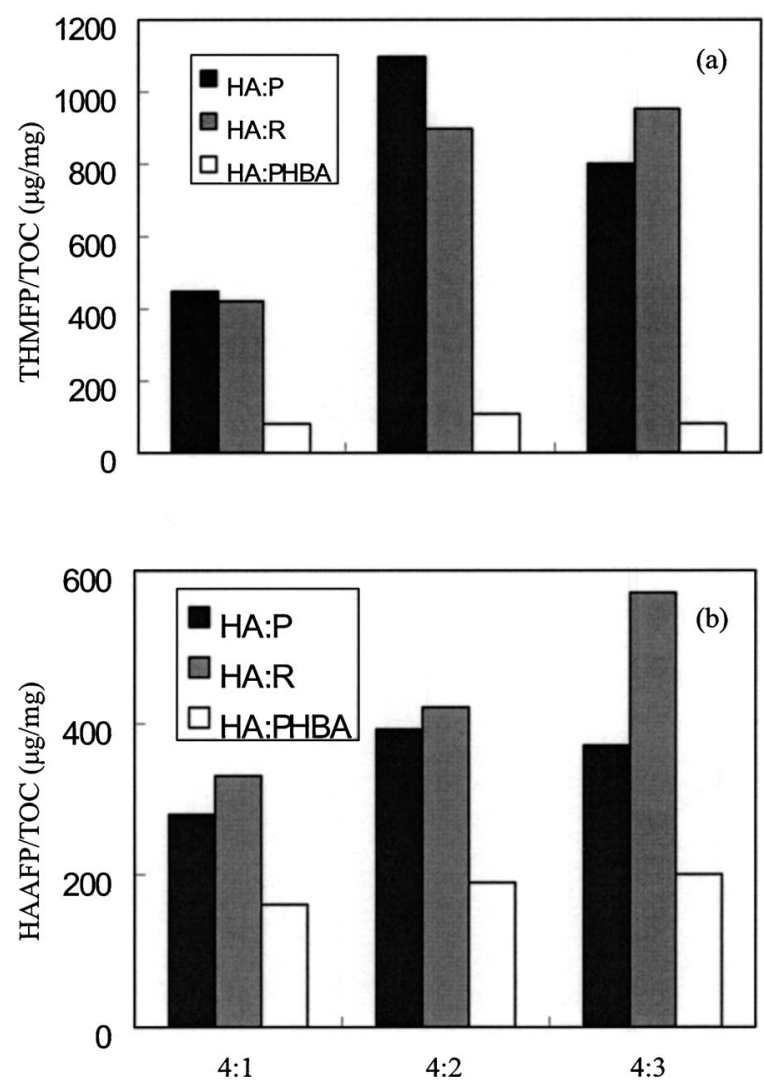

Fig. 8. (a) THM; (b) HAA formation per unit of residual TOC after $168 \mathrm{~h}$ of chlorination at different ratios of humic acid to low-MW compounds

tion. At chlorination time $<30 \mathrm{~h}$, the amount of HAAs formation did not follow the same trend; the HAA amounts were increased steadily as the reaction time increased, as shown in Fig. 7. Compared with Fig. 6(b), it was found that the amount of HAAs was about half of the DBP magnitude, indicating that HAA was the major product after chlorinating the $\mathrm{HA}$ and $\mathrm{R}$.

As shown in Figs. 8(a and b), with a ratio of 4:2 (HA:P), the bicompounds of HA and $\mathrm{P}$ had higher DBP formation per unit of residual TOC, in which the average of specific THMFP and HAAFP (defined as HAAs concentration after $168 \mathrm{~h}$ per residual TOC) were 1,086 and $370 \mu \mathrm{g} / \mathrm{L} / \mathrm{mg} / \mathrm{L}$, respectively. With the ratio of 4:3 (HA:P), the average THMFP and HAAFP were 767 and $350 \mu \mathrm{g} / \mathrm{L} / \mathrm{mg} / \mathrm{L}$, respectively. It might be explained that the DBP formation of $4: 3$ was observed lower than that of $4: 2$ (HA:P), indicating that $\mathrm{P}$ was partly removed from the complex formation during the coagulation process and consequently reduced the DBPs formation level after chlorination at the ratio of 4:3 (HA:P). When comparing the concentration between HAAs and THMs after $168 \mathrm{~h}$ of chlorination, generally the HAAFP was approximately half that of the THMFP.

\section{Conclusions}

The coagulation process was found to be very effective for the removal of turbidity $(95 \%)$ and TOC $(>70 \%)$ for samples containing HA and TA. However, for the cases of samples containing $\mathrm{R}, \mathrm{P}$, and PHBA, the TOC removal rates were not as good as HA and TA, indicating that the coagulation of low-MW target compounds was unfavorable. Although the turbidity and TOC could reach certain levels of removal after coagulation, the efficiency of low-MW model compound removal was not remarkable, which was opposed to the hypothesis, i.e., the increasing ratio of HA to $\mathrm{P}$ ( $\mathrm{R}$ and PHBA) could enhance the removal of low-MW model compounds.

The developed DOC removal model could provide a reasonable assumption to express the phenomenon of DOC adsorption onto metal hydroxide flocs during the coagulation process and resulted in predicting DOC removal successfully. In this developed model, the adsorption capacity $(a)$ is a function of $f_{\text {sorbable }}$ of

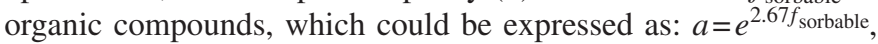
both shown in the nature (Kastl's data) and synthetic water (this study) samples. The $f_{\text {nonsorb }}$ increased as the MW of the target compounds decreased, suggesting that the low-MW target compounds could not be easily adsorbed on the flocs.

The total DBP concentration generally increased as the reaction time increased. The order of chlorine consumption/demand after 168 hour is: $\mathrm{P} \cong \mathrm{PHBA} \gg \mathrm{R}>\mathrm{HA}>\mathrm{TA}$, while the order of chloroform formation is $\mathrm{R}>\mathrm{P} \gg \mathrm{PHBA} \gg \mathrm{HA}>\mathrm{TA}$. For the bicompound system, as the ratio of HA to low-MW compounds increased from $4: 1$ to $4: 3$, the DBP concentrations increased accordingly and the differences between them were significant. It also could be observed that the decreasing trends of THMFP and HAAFP changed from an average of 1,086 and 370 to 767 and $350(\mu \mathrm{g} / \mathrm{L}) / \mathrm{TOC}(\mathrm{mg} / \mathrm{L})$ as the ratio changed from $4: 2$ to $4: 3$, respectively. The order of THM (or HAA) formation is $\mathrm{R}>\mathrm{P}>\mathrm{PHBA}>\mathrm{HA}>\mathrm{TA}$, which is strictly dependent upon the nature of the model compounds.

\section{Acknowledgments}

The support of this project by the National Science Council (Project No. NSC 93-2211-E-038-001) of the Executive Yuan is gratefully acknowledged.

\section{References}

American Public Health Association (APHA). (1998). Standard methods for the examination of water and wastewater, 20th Ed., APHA, Washington, D.C.

Bekbolet, M., et al. (2005). "Application of oxidative removal of NOM to drinking water and formation of disinfection by-products." Desalination, 176(1-3), 155-166.

Chang, E. E., Chiang, P. C., Tang, W. Y., Chao, S. H., and Hsing, H. J. (2004). "Effects of polyelectrolytes on reduction of model compounds via coagulation." Chemosphere, 58(8), 1141-1150.

Chaiket, T., Singer, P. C., Miles, A., Moran, M., and Pallotta, C. (2002). "Effectiveness of coagulation, ozonation, and biofiltration in controlling DBPs." J. Am. Water Works Assoc., 94(12), 81-95.

Collins, M. R., Amy, G. L., and Steenlink, C. (1986). "Molecular weight distribution, carboxylic acidity, and humic substances content of aquatic organic matter: Implications for removal during water treatment." Environ. Sci. Technol., 20(10), 1028-1032.

Cook, R. L., and Langford, C. H. (1998). "Structural characterization of a fulvic acid and a humic acid using solid-state ramp-CP-MAS ${ }^{13} \mathrm{C}$ nuclear magnetic resonance." Environ. Sci. Technol., 32(5), 719-725.

Gallard, H., and Gunten, U. V. (2002). "Chlorination of natural organic matter: Kinetics of chlorination and of THM formation." Water Res. $36(1), 65-74$.

Kastl, G., Sathasivan, A., Fisher, I., and van Leeuwen, J. (2004). "Modeling DOC removal by enhanced coagulation." J. Am. Water Works Assoc., 96(2), 79-89.

Larson, R. A., and Rockwell, A. L. (1979). "Chloroform and chlorophe- 
nol production by decarboxylation of natural acids during aqueous chlorination." Environ. Sci. Technol., 13(3), 315-319.

O'Melia, C. R., Becker, W. C., and Au, K. K. (1999). "Removal of humic substances by coagulation." Water Sci. Technol., 40(9), 47-54.

Plummer, J. D., and Edzwald, J. K. (2001). "Effect of ozone on algae as precursors for trihalomethane and haloacetic acid production." Water Sci. Technol., 35(18), 3661-3668.

Ratnaweera, H., Gjessing, E., and Oug, E. (1999). "Influence of physicalchemical characteristics of natural organic matter (NOM) on coagulation properties: An analysis in eight Norwegian water sources." Water Sci. Technol., 40(9), 89-95.

Rook, J. J. (1976). "Haloforms in drinking water." J. Am. Water Works Assoc., 68(3), 168-172.

Singer, P. C. (1999). "Humic substances as precursors for potentially harmful disinfection by-products." Water Sci. Technol., 40(9), 25-30.

States, S., and Tomko, R. J. (2002). "Enhanced coagulation and removal of Cryptosporidium." J. Am. Water Works Assoc., 94(11), 67-77.
Tang, W.-Y. (2003). "Removal of THM precursors by enhanced coagulation." MS thesis, National Taiwan Univ., Taipei, Taiwan, R.O.C.

Tseng, T., and Edwards, M. (1999). "Predicting full-scale TOC removal." J. Am. Water Works Assoc., 91(4), 159-170.

U.S. Environmental Protection Agency (USEPA). (1995). "Method 552.2: Determination of haloacetic acids and dalapon in drinking water by liquid-liquid extraction, derivatization, and gas chromatography with electron capture detection-Methods for the determination of organic compounds in drinking water." Supplement III, EPA-600/R-95-131, USEPA, Washington, D.C.

van Leeuwen, J., Daly, R., and Holmes, A. (2005). "Modeling the treatment of drinking water to maximize dissolved organic matter removal and minimize disinfection by-product formation." Desalination, 176(1-3), 81-89.

White, M. C. (1997). "Evaluation criteria for enhanced coagulation compliance." J. Am. Water Works Assoc., 89(5), 64-73. 